\title{
ENGLISH LANGUAGE TEACHERS' PERCEPTIONS OF HYBRID LEARNING AT UNIVERSITY LEVEL
}

\author{
Tetiana Vereshchahina \\ Didactic Centre of Fribourg University, Fribourg, Switzerland \\ vereschagina_tet@ukr.net \\ Olesia Liashchenko \\ Taras Shevchenko National University, Kyiv, Ukraine \\ lyashchenko1981@ukr.net \\ Serhij Babiy \\ Taras Shevchenko National University, Kyiv, Ukraine \\ babii_08@ukr.net
}

\begin{abstract}
The rapid growth of modern technologies has facilitated the emergence of hybrid learning as a specially designed training system that combines face-to-face learning and remote phase. Since this teaching mode is relatively new to university English language instructors, there is an urgent need to investigate ESL teachers' perceptions of hybrid learning at university level. Therefore, the purpose of this pilot study is to analyse the teachers' self-assessment of TPACK (Technological, Pedagogical and Content Knowledge) as an important prerequisite of successful incorporation of computer technologies and I-tools into a curriculum, and consider advantages and disadvantages of hybrid learning in university teachers' working environments. The analysis of quantitative and qualitative data has revealed that teachers have high content, pedagogical and pedagogical content knowledge whereas technological knowledge and technological content knowledge appear to be lower. The latter can be explained by the lack of information support and relevant digital classroom equipment in their educational institutions as it was indicated in the list of disadvantages. At the same time, the teachers' responses have shown that advantages (a student-centred approach, an easy access to learning materials and assessment criteria, a wide range of online tools to learn English) outnumber the disadvantages. In general, the ESL teachers' perceptions of hybrid learning are positive. However, they need to improve their technological knowledge and technological content knowledge. Also, better-equipped classrooms could create more favourable learning environments. Positive changes in these spheres could lead to the more effective implementation of hybrid learning in teaching English at university level.
\end{abstract}

Keywords: TPACK; hybrid learning; higher education; English as a Second Language.

\section{Introduction}

The growth of virtual technologies provides pedagogues with qualitatively new teaching and learning possibilities when distance and face-to-face modes of learning are conjointly incorporated into a hybrid course. It is considered to be an innovation in this moment of education development, representing a link between face-to-face and virtual teaching approaches (Jézégou, 2014). Assumingly, it helps to keep a positive aspect of in-class learning and enriches the process of learning with different asynchronous possibilities. Although this teaching delivery mode has been increasingly applied in higher education in the last few decades, it has been breaking fresh ground in Ukrainian higher educational institutions. Thus, the introduction of hybrid learning is urgent for Ukrainian teachers as a way to enrich their teaching methods and for students as a tool to obtain high-level professional knowledge. Moreover, this issue is of great importance in teaching English as a Second Language (ESL), either for General Purposes or Special Academic Purposes. The reasons for using hybrid learning mode in teaching ESL are numerous: the growing increase and free availability of online tools for mastering reading, listening, writing, and speaking skills; a demand to deal with authentic visual, audio and video materials to strengthen students' motivation, engagement, and professional knowledge; a need to overcome a 'generation gap' between digital natives (students) and digital emigrants (teachers), etc. In the recent literature on the subject, the main emphasis has been mainly put on student experience in the analysis and measurement of hybrid learning effectiveness while academic experience has remained an insufficiently explored sphere (Jeffrey at all, 2014; Torrisi-Steel \& Drew, 2013). In the meanwhile, responses from academic staff on their personal experience of using modern computer technologies and online tools in teaching can contribute to the improved understanding of teachers' confidence and capability to use hybrid learning mode and also help to consider crucial factors that facilitate or hinder this innovative teaching practice in their working environment.

It is essential for university lecturers to have sound content, pedagogical and technological skills in order to successfully implement a hybrid learning mode in the digital age. Thus, according to the conceptualisation of TPACK (Technological Pedagogical and Content Knowledge), there are three aspects of 
effective teaching knowledge: technological, pedagogical and content knowledge, as posited by Koehler et al (2014). Content knowledge (CK) is subject knowledge, which a teacher is supposed to teach according to one's educational qualifications and job responsibilities. Pedagogical knowledge (PK) refers to a teacher's knowledge about various pedagogical methodologies and teaching practices. Technology knowledge (TK) is a teacher's knowledge about traditional and computer-mediated technologies that can be incorporated into teaching. These three aspects do not exist separately but complement each other and create other kinds of knowledge such as 1) Technological Content Knowledge (TCK) that relates to a teacher's knowledge about the effective use of technologies to deliver subject knowledge to the target audience; 2) Pedagogical Content Knowledge (PCK) that refers to a teacher's knowledge about appropriate and effective pedagogical instructions and approaches to teaching content knowledge with regard to learning styles and abilities of target audience; 3) Technological Pedagogical Knowledge (TCK) that can be defined as a teacher's knowledge about the effective use of technologies in order to enrich one's pedagogical practices; Technological Pedagogical Content Knowledge (TPACK) is knowledge about the ways to effectively combine the above-mentioned kinds of knowledge in order to reach learning goals according to the curriculum. "The TPACK framework suggests that teachers need to have deep understanding of each of the above components of knowledge in order to orchestrate and coordinate technology, pedagogy, and content into teaching." (Koehler et al, 2014, p.102).

The interaction of the aspects of knowledge, technology, pedagogy, and content creates the kind of flexible knowledge in teachers that is required to apply technology in teaching practice (Koehler et al, 2014). This idea is applicable to hybrid learning approach, where the combination of e-learning and face-to-face learning requires from teachers a kind of new teaching knowledge to be performed both in the classroom and virtually. Therefore, in the present article, the interpretation of hybrid learning is based on the TPACK theory when different technological, pedagogical and content knowledge enable teachers to design and apply a hybrid learning environment. Assumingly, the level of the types of knowledge stated above varies among teachers and it is crucial to measure it and detect the strongest and weakest points of face-to-face and virtual learning components. Thus, in the current research, the level of hybrid learning is defined as the level of Technological, Pedagogical, and Content knowledge applied by teachers in the classrooms and virtually.

Therefore, the main purpose of this article is to define the university ESL teachers' self-perceived level of hybrid learning through analysing Technological, Pedagogical and Content Knowledge applied by them in their teaching practice and consider advantages and disadvantages of hybrid learning in their educational institutions on the basis of teachers' observations. The following tasks have facilitated the achievement of the purpose:

- to analyse scientific literature concerning the definition, key conceptual elements, and functions of 'hybrid learning';

- to conduct a quantitative survey of in-service university lecturers about their TPACK;

- to carry out a qualitative survey of in-service university lecturers on computer-mediated technologies they use in their teaching practice, collect feedbacks about advantages and disadvantages of hybrid learning, and obtain data about their ideas how this mode of teaching could be improved at the university level.

\section{Theoretical background}

The notion of hybrid learning is relevantly new in the education science literature and that is why there may be a mismatch of interpretations among researchers. There can be found terms of blended and hybrid learning in pedagogical discourse. However, most of the authors agree that they may be used interchangeably (Graham \& Dziuban, 2008; Usova, 2011; O'Byrne et al., 2015). Thus, the term hybrid learning is used in the present article.

Concerning the definition of hybrid learning, there is no common view among researchers in the big variety of interpretations. Graham and Dziuban (2008) comment that blended learning environments combine face-to-face teaching with technology-mediated teaching. Some authors (Fenton \& Watkins, 2010) argue that teachers' use of blended learning is the innovative form of classroom practice. In their turn, Pombo and Moreira (2010) define blended learning as a combination of pedagogical concepts depending on the focus: a compound of pedagogical strategies, supporting technologies, and/or teaching delivery modes. Considering above-mentioned ideas, it may be assumed that hybrid learning may be applied as a combination of different pedagogical aspects.

Significantly, hybrid learning may also be interpreted as the systemic incorporation of classroom and distance phases of a course. We follow the idea of Charlier et al. (2012) who state that hybrid learning is an entire educational programme that combines face-to-face and remote phases. This idea is also supported by Peterson and McGuire (2014) who apply the term hybrid learning to refer to the entire programme structure, 
not only a combination of online and face-to-face modes of teaching. Also, Kukharenko (2013) mentions two types of interpretation of hybrid learning: 1) in a narrow sense, it stands for a combination of elements from traditional and online courses; 2) in a broader sense, "this is a teaching methodology, a delivery, and an approach that combines traditional methods in the classroom with computer-mediated learning activities. The strengths of this method are the combination of different technologies into a single integrated learning approach" (p. 50). So, it may be assumed that many researchers understand the issue of hybrid learning as an entire programme or system that combines classroom and virtual phases.

Thus, hybrid learning is a new important pedagogical paradigm that encompasses a new learning environment, instruction design, and teacher-student relations. It might be quite beneficial since it allows students to use the advantages of physical and virtual learning environments. Ideally, "good virtual learning environments offer: 1) time flexibility for both students and teachers; 2) easy access to curriculum and learning materials $24 / 7$; 3) communication in three formats: a student-a teacher, a group of students-a teacher, peer-group communication; 4) collaboration in online group or pair projects; 5) more independence for a learner; 6) convenient assessment and feedback modes for a teacher; 7) easy tracking of students' progress and achievement; 8) availability of supplementary materials. It is a good system for learners with different levels of knowledge. Thus, weaker students can revise material and redo exercises while stronger learners can take advantage of additional resources to get a deeper insight into a subject. Students with different learning styles can choose from a number of options that are suitable for them. The last but not the least advantage we would like to mention is that hybrid learning facilitates a transition from a 'teachercentred' classroom to a 'learner-centred' format and shapes the environment of co-learning" (Liashchenko \& Babiy, 2017, pp. 94-95). Students can acquire skills during the course and interact with peers, share their ideas and complete practical tasks. However, it is crucial to keep in mind that all the above-mentioned advantages of hybrid learning are hard to obtain without solid technological, pedagogical and content knowledge of teachers who design and manage a learning environment for students. In this article, we assume a direct connection between the level of ESL teachers' Technological, Pedagogical, and Content knowledge and the level of hybrid learning they deliver to students. The studies by Koehler and Mishra (2005), Graham et al (2009), Chai et al (2013), Jimoyiannis (2010), Khan (2011) have emphasised the importance of TPACK for integrating ICT in the classroom and virtual environment. The higher TPACK teachers have, the better their capability is to use modern computer-mediated technologies and online tools in their teaching practice.

\section{Methodology}

A methodological basis of the literature analysis for this pilot study rests on general scientific principles of objectivity and systematicity. Quantitative data were administered through SPSS statistics program. Descriptive statistics were used to analyse the results of the quantitative survey. As for the data of a qualitative survey, the answers were coded and categorised using a qualitative approach.

The data collection from university lecturers was conducted on the basis of quantitative and qualitative questionnaires. The first used questionnaire was developed by Baser, Kopcha \& Ozden (2015) on the basis of TPACK concept and is aimed at self-assessment of English Language Instructors' Technological Pedagogical Content Knowledge. Apart from standard demographic inquiries, it features 39 questions that fall into such categories as

- Technological Knowledge (1-9 Qs), which tests teachers' knowledge of basic computer terms, skills to eliminate problems with an Internet connection and other typical technical glitches, ability to use basic office software programs (Word, Excel, PowerPoint, Picture Manager) and desire to learn new technologies;

- Content Knowledge (10-14 Qs), in which teachers are asked to assess their listening, reading, writing and speaking skills in the English Language;

- Pedagogical Knowledge (15-20 Qs), which tests the knowledge about traditional and emerging methods and approaches used in foreign language teaching;

- Pedagogical Content Knowledge (21-25 Qs), in which teachers are supposed to assess their knowledge of pedagogical methods that are relevant to the specific subjects (i.e. Geo English, Medical English) they teach;

- Technological Content Knowledge (26-28 Qs), which helps assess whether teachers know how to use computer technologies effectively in teaching various issues (i.e. Plate Tectonics, Structure of Human Cell, Pests, and Pesticides, etc.);

- Technological Pedagogical Knowledge (29-35 Qs), which tests the knowledge about a reasonable blend of computer technologies with efficient pedagogical methods; 
- Technological Pedagogical Content Knowledge (36-39 Qs), which tests skills to successfully combine content of the academic discipline, effective teaching methods and adequate usage of computer technologies in order to achieve educational goals.

English Language instructors have been asked to evaluate their skills using a 9-point scale, in which:

1 point -3 points stand for the initial level of skills and abilities;

4 points -6 points stand for the medium level of skills and abilities;

7 points -9 points stand for the high level of skills and abilities.

Firstly, descriptive statistics were used to analyse the data and present the means and standard deviations. Also, to this questionnaire 2 open-ended questions were added by the authors of the article. These questions are the following:

1. What technical facilities in the classroom and multimedia tools on the Internet do you use in teaching General English or English for Specific Purposes?

2. What technical equipment in the classroom and multimedia tools on the Internet are used by your students to learn General English or English for Specific Purposes?

Apart from it, in another questionnaire teachers were asked to comment on the advantages and disadvantages of hybrid learning practice in their educational institutions.

In order to analyse answers to open-ended questions, we coded them according to the following categories: Usage of Modern Technologies - student items; Usage of Modern Technologies, Advantages of Hybrid Learning, Disadvantages of Hybrid Learning - teacher items.

\section{Participants}

In this pilot study, the data was collected from 18 tertiary English Language instructors of Taras Shevchenko National University of Kyiv and National University of Life and Environmental Sciences of Ukraine. All of them have had experience in teaching hybrid courses of ESL.

\section{Results}

In the present article, the level of hybrid learning reported by university teachers is examined in seven teaching dimensions which embrace teachers' technology, pedagogy, and content knowledge. The combination of this knowledge constitutes teaching competencies in the context of the hybrid approach to education. This can help to define the extent to which teachers are aware of the hybrid approach to education and how successfully they put it into practice. It may be helpful in identifying some problematic issues in the implementation of the hybrid framework in the classroom and become the basis for further research.

The total level of hybrid learning is demonstrated with the Figure 1 when Technological Knowledge and Technological Content Knowledge items have the lowest mean values $(\mathrm{M}=6,28$ and $\mathrm{M}=6,9 ; \mathrm{SD}=1,38$; $\mathrm{SD}=1,47)$ and Content Knowledge has the highest self-perceived level $(\mathrm{M}=8,36 ; \mathrm{SD}=0,76)$. However, the other dimensions of the study (Pedagogical Knowledge, Pedagogical Content Knowledge) are also detected to be high. This result may be interpreted as teachers tend to be more competent in the content knowledge of the discipline they teach and different pedagogical aspects rather than in learning technologies dimensions.

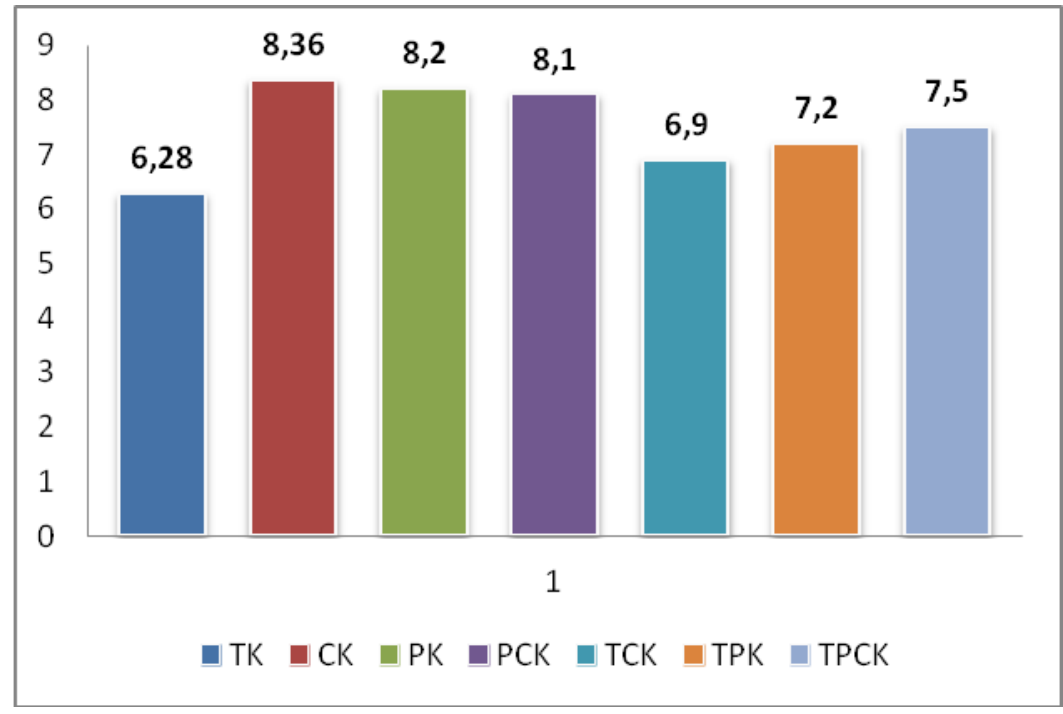

Figure 1. The level of university teachers' perceptions of hybrid learning 
Regarding the detailed description of Technological Knowledge dimension (Table 1), it is important to admit the minimum mean value $(M=4,2 ; \mathrm{SD}=2,3)$ and maximum mean value $(\mathrm{M}=7,8 ; \mathrm{SD}=0,83)$ on the possible range from 1 to 9 . Teachers tend to have the medium level in the items concerning the creation of multimedia tools and using collaboration tools in the process of their teaching practice. At the same time, teachers show the high level of computer peripherals application and basic technological terms. All in all, technological knowledge reported by teachers is perceived to be of average to the high level. However, none of the respondents reported themselves as excellent users of learning technologies with the highest grades of 8 and 9.

\section{Technological Knowledge}

Table 1

\begin{tabular}{|l|l|l|}
\hline & \multicolumn{1}{|c|}{ Mean } & \multicolumn{1}{|c|}{$\begin{array}{c}\text { Std. } \\
\text { Deviation }\end{array}$} \\
\hline $\begin{array}{l}\text { I can use basic technological terms (e.g., operating system, wireless } \\
\text { connection, virtual memory, etc.) appropriately. }\end{array}$ & 7,222 & 1,8005 \\
\hline $\begin{array}{l}\text { I can adjust computer settings such as installing software and establishing } \\
\text { an Internet connection. }\end{array}$ & 6,2778 & 2,32140 \\
\hline $\begin{array}{l}\text { I can use computer peripherals such as a printer, a headphone, and a } \\
\text { scanner. }\end{array}$ & 7,8889 &, 83235 \\
\hline $\begin{array}{l}\text { I can troubleshoot common computer problems (e.g., printer problems, } \\
\text { Internet connection problems, etc.) independently. }\end{array}$ & 6,0556 & 2,48459 \\
\hline I can use digital classroom equipment such as projectors and smart boards & 6,5000 & 2,22948 \\
\hline $\begin{array}{l}\text { I can use Office programs (i.e. Word, PowerPoint, etc.) with a high level of } \\
\text { proficiency. }\end{array}$ & 6,9444 & 1,55193 \\
\hline $\begin{array}{l}\text { I can create multimedia (e.g. video, Web pages, etc.) using text, pictures, } \\
\text { sound, video, and animation. }\end{array}$ & 4,8333 \\
\hline $\begin{array}{l}\text { I can use collaboration tools (wiki, Edmodo, 3D virtual environments, etc.) } \\
\text { in accordance with my objectives. }\end{array}$ & 4,2222 & 2,66237 \\
\hline $\begin{array}{l}\text { I can learn software that helps me complete a variety of tasks more } \\
\text { efficiently. }\end{array}$ & 6,5000 & 2,39007 \\
\hline Valid N (listwise) & 18 & \\
\hline
\end{tabular}

Concerning the next dimension of Content Knowledge, it is possible to assume that teachers perceive their content knowledge as high (Table 2). The highest mean score $(\mathrm{M}=8,6 ; \mathrm{SD}=0,6)$ is for understanding the written text in English and the lowest $(\mathrm{M}=8 ; \mathrm{SD}=0,9)$ for understanding native speakers. As a result, all the respondents reported their level of content knowledge as high.

Table 2

\section{Content Knowledge}

\begin{tabular}{|l|l|l|}
\hline \multicolumn{1}{|c|}{ Statements } & Mean & \multicolumn{1}{|c|}{$\begin{array}{c}\text { Std. } \\
\text { deviation }\end{array}$} \\
\hline I can express my ideas and feelings by speaking in English. & 8,2778 & 1,27443 \\
\hline I can express my ideas and feelings by writing in English & 8,3889 &, 97853 \\
\hline I can read texts written in English with the correct pronunciation. & 8,5000 &, 78591 \\
\hline I can understand texts written in English. & 8,6111 &, 60768 \\
\hline I can understand the speech of a native English speaker easily. & 8,0000 &, 97014 \\
\hline Valid N (listwise) & 18 & \\
\hline
\end{tabular}

Teachers' Pedagogical Knowledge (Table 3) is also reported to be high. The highest reported grade $(\mathrm{M}=8,4 ; \mathrm{SD}=0,61)$ is for the ability to collaborate with school stakeholders and the lowest score $(\mathrm{M}=7,8$; $\mathrm{SD}=1,1)$ is for using adequate teaching methods and techniques. Generally, most of the respondents perceive the high level of content knowledge.

Concerning Pedagogical Content Knowledge, this dimension is also reported to be high (Table 4). The highest perceived score $(\mathrm{M}=8,2 ; \mathrm{SD}=0,9)$ for preparing curricular activities item. The item of application 
teaching methods to support students in developing their language skills has a lower score $(\mathrm{M}=8 ; \mathrm{SD}=0$, 84). Thus, the total level of PCK skills is high.

Table 3

\section{Pedagogical Knowledge (PK)}

\begin{tabular}{|l|l|l|}
\hline \multicolumn{1}{|c|}{ Statements } & Mean & $\begin{array}{l}\text { Std. } \\
\text { deviation }\end{array}$ \\
\hline $\begin{array}{l}\text { I can use teaching methods and techniques that are appropriate for a } \\
\text { learning environment. }\end{array}$ & 7,8333 & 1,15045 \\
\hline $\begin{array}{l}\text { I can design a learning experience that is appropriate for the level of } \\
\text { students. }\end{array}$ & 8,1667 & 1,04319 \\
\hline $\begin{array}{l}\text { I can support students' learning in accordance with their physical, mental, } \\
\text { emotional, social, and cultural differences. }\end{array}$ & 8,2222 &, 80845 \\
\hline $\begin{array}{l}\text { I can collaborate with school stakeholders (students, parents, teachers, } \\
\text { etc.) to support students' learning. }\end{array}$ & 8,4444 &, 61570 \\
\hline $\begin{array}{l}\text { I can reflect the experiences that I gain from professional development } \\
\text { programs to my teaching process. }\end{array}$ & 8,1667 &, 78591 \\
\hline $\begin{array}{l}\text { I can support students' out-of-class work to facilitate their self-regulated } \\
\text { learning. }\end{array}$ & 8,3333 &, 76696 \\
\hline Valid N (listwise) & 18 & \\
\hline
\end{tabular}

\section{Pedagogical Content Knowledge}

Table 4

\begin{tabular}{|l|l|l|}
\hline \multicolumn{1}{|c|}{ Statements } & Mean & $\begin{array}{l}\text { Std. devia } \\
\text { tion }\end{array}$ \\
\hline I can manage a classroom learning environment. & 8,1111 &, 83235 \\
\hline I can evaluate students' learning processes. & 8,3333 &, 68599 \\
\hline $\begin{array}{l}\text { I can use appropriate teaching methods and techniques to support students } \\
\text { in developing their language skills. }\end{array}$ & 8,0000 &, 84017 \\
\hline I can prepare curricular activities that develop students' language skills. & 8,2222 &, 87820 \\
\hline $\begin{array}{l}\text { I can adapt a lesson plan in accordance with students' language skill } \\
\text { levels. }\end{array}$ & 8,1667 &, 70711 \\
\hline Valid N (listwise) & 18 & \\
\hline
\end{tabular}

Concerning the level of Technological Content Knowledge shown in the Table 5, it is possible to assume that the level of technological content knowledge is medium. For example, the application of collaboration tools is estimated as $\mathrm{M}=5(\mathrm{SD}=2,54)$ that is the lowest value and application of multimedia is assessed with the highest value $(\mathrm{M}=7,11 ; \mathrm{SD}=1,32)$. Application of distance to multilingual technologies is also detected as medium levelled. Taking into account the above-mentioned results, the respondents may feel a lack of technological content knowledge in their teaching practice.

Technological Content Knowledge (TCK)

Table 5

\begin{tabular}{|l|l|l|}
\hline \multicolumn{1}{|c|}{ Statements } & Mean & Std. deviation \\
\hline $\begin{array}{l}\text { I can take advantage of multimedia (e.g. video, slideshow, etc.) to } \\
\text { express my ideas about various topics in English. }\end{array}$ & 7,1111 & 1,32349 \\
\hline $\begin{array}{l}\text { I can benefit from using technology (e.g. web conferencing, discussion } \\
\text { forums) to contribute at a distance to multilingual communities. }\end{array}$ & 6,1667 & 2,12132 \\
\hline $\begin{array}{l}\text { I can use collaboration tools to work collaboratively with foreign } \\
\text { persons (e.g. Second Life, wiki, etc.). }\end{array}$ & 5,0000 & 2,54374 \\
\hline Valid N (listwise) & 18 & \\
\hline
\end{tabular}


Respondents participated in the study reported their level of Technological Pedagogical Knowledge as upper-medium to high. For example, they estimate the usage of virtual discussion platforms as upper medium $(\mathrm{M}=5,77 ; \mathrm{SD}=2,3)$ that is the lowest point. However, the question of designing learning material with new technologies is assessed as high $(\mathrm{M}=8 ; \mathrm{SD}=1,02)$. As it can be seen from the Table 6 , most of the participants evaluated this teaching dimension as relevantly high.

Table 6

Technological Pedagogical Knowledge (TPK)

\begin{tabular}{|l|l|l|}
\hline \multicolumn{1}{|c|}{ Statements } & Mean & Std. deviation \\
\hline $\begin{array}{l}\text { I can meet students individualised needs by using information } \\
\text { technologies. }\end{array}$ & 7,2778 & 1,07406 \\
\hline $\begin{array}{l}\text { I can lead students to use information technologies legally, ethically, } \\
\text { safely, and with respect to copyrights. }\end{array}$ & 6,9444 & 1,95455 \\
\hline $\begin{array}{l}\text { I can support students as they use technology such as virtual discussion } \\
\text { platforms to develop their higher order thinking abilities. }\end{array}$ & 5,7778 & 2,34033 \\
\hline $\begin{array}{l}\text { I can manage the classroom learning environment while using } \\
\text { technology in the class. }\end{array}$ & 7,6111 & 1,24328 \\
\hline $\begin{array}{l}\text { I can decide when technology would benefit my teaching of specific } \\
\text { curricular standards. }\end{array}$ & 7,8333 & 1,42457 \\
\hline $\begin{array}{l}\text { I can design learning materials by using technology that supports } \\
\text { students' learning. }\end{array}$ & 8,0000 & 1,02899 \\
\hline $\begin{array}{l}\text { I can use multimedia such as videos and Web sites to support students' } \\
\text { learning. }\end{array}$ & 7,1111 & 1,60473 \\
\hline Valid N (listwise) & 18 & \\
\hline
\end{tabular}

Similar to the previous dimension, teachers' Technological Pedagogical Content Knowledge may be regarded as high (table 7). All the items are ranked as high levelled. The support of professional development by use of a technological tool is the highest ranked item $(\mathrm{M}=7,67 ; \mathrm{SD}=1,53)$. And the item of collaboration tools application if relatively lower ranked $(\mathrm{M}=7,61 ; \mathrm{SD}=0,91)$.

\section{Technological Pedagogical Content Knowledge (TPACK)}

Table 7

\begin{tabular}{|l|l|l|}
\hline \multicolumn{1}{|c|}{ Statements } & Mean & Std. deviation \\
\hline $\begin{array}{l}\text { I can use collaboration tools (e.g. wiki, 3D virtual environments, etc.) to } \\
\text { support students' language learning. }\end{array}$ & 7,6111 & 1,91644 \\
\hline $\begin{array}{l}\text { I can support students as they use technology to support their development } \\
\text { of language skills in an independent manner. }\end{array}$ & 7,1667 & 1,61791 \\
\hline $\begin{array}{l}\text { I can use Web 2.0 tools (animation tools, digital story tools, etc.) to } \\
\text { develop students' language skills. }\end{array}$ & 7,5556 & 1,29352 \\
\hline $\begin{array}{l}\text { I can support my professional development by using technological tools } \\
\text { and resources to continuously improve the language teaching process. }\end{array}$ & 7,6667 & 1,53393 \\
\hline Valid N (listwise) & 18 & \\
\hline
\end{tabular}

Thus, teachers tend to have a lower level of technological knowledge and technological content knowledge in comparison with the other dimensions of the study. Although the main results are reported to be high and upper medium, there are some particular items with the lower level. For example, respondents estimated the creation of multimedia resources, collaboration tools including visual conferences, wikis, Second Life etc. as the lowest compared to others. This may be assumed that teachers feel a lack of awareness and practical skills in using collaboration tools and multimedia resources. The total lower level of technical skills may also be explained with an insufficient level of technical equipment provided in the university classrooms.

The overall upper-medium and high level of hybrid learning approach applied in the university may be interpreted as an overestimation of one's teaching skills and lack of self-criticism and may be explained by the limitations inherent to Likert scales. Additionally, social desirability in some answers and small sample size 
can also become a limitation for the present study. Therefore, the above-stated limitations and resources available to the authors don't allow generalising the results; however, this study can become a background for further research.

\section{Discussion}

Besides taking part in a quantitative survey, teachers were asked a number of open-ended questions. The answers to the first question about computer-mediated tools the teachers and their students use in and beyond the classroom revealed that all the teachers use such technological tools as laptops, CD-players in the classrooms. As for I-tools, the most frequently mentioned were Powerpoint, video channels (TeacherTube, SchoolTube, YouTube, etc.) Blogs, Wikis, and Google Docs. Also, TED, Slideshare, Quizlet and online journals are used quite often. As for rarely used I-tools, such internet resources as Voice Thread, Online Quiz Creator, Hot Potatoes, Spelling City, Elmondo, Wordle, Animoto, and Flickr were mentioned. In their turn, students mostly use laptops and Powerpoint to make and deliver presentations. Also, they frequently use Google Docs, video channels and sometimes Blogs and Quizlet depending on the instructions they are given.

Furthermore, the teachers shared their perceptions of the factors that hinder and facilitate hybrid learning.

The weaknesses appeared to be the following:

1. Students can cheat when performing online tests, copy keys to the tasks or plagiarise resources from the Internet. It is hard to check beyond a classroom whether they did tasks on their own or used someone's help.

2. It is hard to control students' speaking skills through the online learning phase.

3. Students (especially those at the A1-A2 level of English) often fail to comprehend grammar rules without teacher's help and, consequently, fail to write tests correctly in the classroom.

4. Students often fall behind the schedule by sending their homework to teachers.

5. If students send photos of their homework, the quality of photos can be so poor or handwriting so indistinguishable, that it is hard for a teacher to assess the work objectively.

6. It is often time-consuming for a teacher to prepare materials for students' self-study, which basically repeats the main structure of the curriculum, but needs more tasks to include.

7. It is time-consuming to send feedback to students individually about common mistakes that many of them made.

On the plus side the following ideas emerged:

1. Flexible learning process. As one of the teachers put it, hybrid learning "allows students to work at their own pace from their comfortable homes as well as take a break when they need it."

2. Time in class can be used more effectively: group work, discussions and so on.

3. It is more student-centred as it motivates students' self-control and self-study.

4. It increases students' engagement. For example, students are more interested in making presentations than reading traditional reports.

5. It offers a wide range of activities to learn English.

6. It improves the dynamics of lessons.

7. It boosts digital literacy. As one of the teachers described it, "Being able to use online services and technical resources efficiently helps not only you but also people who surround you. In our case, we are talking about colleagues and students whose learning or work becomes easier and more effective. Digital literacy promotes creativity, collaboration, and communication of all stakeholders. As you know, if you are not moving forward, you are moving backward and that means that I, as a teacher, need to master new technologies and be on the same page with my students."

8. It is useful to show videos on science recorded by native speakers - in that way students see better the practical application of professional vocabulary.

9. Flexible assessment of students' academic achievements.

10. It saves teachers' time that is usually spent on explanations.

Besides, the teachers were asked a question "How could learning English through the use of hybrid learning mode be improved in your educational institution?". The following suggestions were shared:

- to equip classrooms with modern technical devices such as projectors and smart boards.

- to provide high-speed wireless Internet connection in classrooms.

- to develop an adequate learning platform to cover all the goals and tasks of the curriculum.

- to organise information support for teachers to facilitate the use of modern computer technologies because it is rather difficult to master modern technologies without professional help.

The answers to open-ended questions show that teachers use basic technical devices (a laptop, a CDplayer, a projector) in the classroom and encourage their students to use laptops for delivering presentations. 
At the same time, teachers pointed out the lack of modern equipment like projectors and smart boards in the classrooms. As for I-tools, video channels (TeacherTube, SchoolTube, YouTube, etc.) Blogs, Wikis and Google Docs turned out to be the most popular. However, the absence of a high-speed Internet connection in the classrooms obviously restricts the teachers' choices. It might be assumed that access to the Internet could allow them to use a wider range of mobile applications and software to learn English. Also, the majority of the teachers voiced their concern about the incorporation of virtual learning platform into their teaching practice. In spite of existing problems, academic staff agreed that the advantages of hybrid learning outnumber its disadvantages, which might be limited to the working environment of their educational institutions. Most importantly, they expressed a desire to go on a training course or receive other types of information support to improve their TPACK. According to Fullan (1991), innovations presuppose changes in teachers' epistemic beliefs and behaviour. In other words, innovative teaching is not only an issue of innovative teaching strategies, computer technologies, and content knowledge but also an issue of how teachers perceive innovation. More specifically, the question of perception is a principal aspect of the interpretation of ideas diffusion (Clinton \& House, 1970). Epistemic factors are crucial for teachers' perception of innovations together with other factors like knowledge or technologies learning. In this pilot study, it has been found that Ukrainian ESL instructors at university level perceive a hybrid learning teaching mode positively and are ready to develop professionally in order to improve the quality of this innovative teaching practice.

\section{Conclusions}

A rapid development of technologies has encouraged the emergence of innovative teaching practices in higher education. One of them, hybrid learning, represents a specially designed environment that combines face-to-face and virtual learning as its key components in a training course. In the article, English language teachers' perceptions of hybrid learning were analysed in three dimensions: self-assessment of TRACK, feedbacks on advantages and disadvantages of hybrid learning, suggestions about the ways to improve the level of this innovative teaching practice. In our pilot study, the data of quantitative and qualitative surveys revealed that ESL university teachers have quite high content, pedagogic and pedagogical content knowledge. However, technological knowledge and technological content knowledge appeared to be rather lower, with an ability to create multimedia resources, collaboration tools including visual conferences, webinars, wikis etc. being the lowest. High figures in other aspects, however, might be partly explained by the lack of self-criticism or the fear to appear incompetent. At the same time, a deep insight into the advantages and disadvantages of hybrid learning, provided by the teachers, clearly shows their keen interest in this innovative teaching practice and positive attitude towards its implementation. Furthermore, an obvious contrast between a wide range of I-tools used by teachers and the lack of modern equipment and high-speed Internet connection in the classrooms allows us to assume that the teachers have good TPACK and are capable of applying hybrid learning at a high level but they are limited in the resources to fully reveal their pedagogic potential. In general, the results of the surveys show that teachers have a positive perception of hybrid learning and are willing to put this educational innovation into practice. However, they need information support concerning the usage of modern I-tools and better technical equipment for classrooms.

Further research on hybrid learning may concern changes to teachers' development programs that would emphasise the importance of solid technological content skills and relevant technical conditions for the effective teaching of the English language at university level.

\section{References:}

Baser, D., Kopcha, T. \& Ozden, M. (2015). Developing a technological pedagogical content knowledge (TPACK) assessment for preservice teachers learning to teach English as a foreign language. Computer Assisted Language Learning, 29 (4),749-764.

Chai, C.-S., Koh, J. H. L., \& Tsai, C.-C. (2013). A Review of Technological Pedagogical Content Knowledge. Educational Technology \& Society, 16(2), 31-51.

Charlier, B. (2012). Academic development in a Swiss university: a private or a public good? Higher Education Research Network Journal: EFAD Special Edition, 5, 77-82.

Clinton, A. \& House, J. H. (1970). Attributes of Innovations as Factors in Diffusion. Paper presented at the American Educational Research Association Annual Meeting, Minneapolis, Minnesota. March 1970. (ERIC Document Reproduction Number. ED 038 347)

Fenton, D. \& Watkins, B. W. (2010). Fluency in distance learning. Charlotte, NC: Information Age Publishing, Inc.

Fullan, M. (1991). The new meaning of educational change (2nd ed.), New York, NY: Teachers College Press.

Graham, C. \& Dziuban, C. (2008). Blended learning environments. In Spector, J.,Merrill, M., Merrienboer, J., Driscoll, M. (Eds.), Handbook of Researchon Educational Communications and Technology (3rd ed.) (pp. 269-274). New York: Taylor \& Francis Group.

Graham, C. R., Burgoyne, N., Cantrell, P., Smith, L., Clair St., L., \& Harris, R. (2009). TPACK development in science teaching: Measuring the TPACK confidence of in-service science teachers. TechTrends, 53(5), 70-79. 
Jeffrey, L. M., Milne, J., Suddaby, G., \& Higgins, A. (2014). Blended learning: How teachers balance the blend of online and classroom components. Journal of Information Technology Education: Research, 13, 121-140. Retrieved from http://www.jite.org/documents/Vol13/JITEv13ResearchP121-140Jeffrey0460.pdf

Jézégou, A. (2014). Regard sur la recherche “dispositifs hybrides dans l'enseignement supérieur” (Hy-Sup): avancées majeures et interprétation possible de la typologie. Education \& Formation - e-301 - Mai 2014, 139-147.

Jimoyiannis, A. (2010). Designing and implementing an integrated technological pedagogical science knowledge framework for science teachers' professional development. Computers \& Education, 55(3), 1259-1269.

Koehler, M. J. \& Mishra, P. (2005). What happens when teachers design educational technology? The development of technological pedagogical content knowledge. Journal of Educational Computing Research, 32(2), 131-152.

Koehler, M. J., Mishra, P., Kereluik, K., Shin, T. S., \& Graham, C. R. (2014). The technological pedagogical content knowledge framework. In J.M. Spector, M.D. Merrill, J. Elen, \& M.J. Bishop (Eds.), Handbook of research on educational communications and technology (pp. 101-111). New York, NY: Springer.

Khan, S. (2011). New pedagogies on teaching science with computer simulations. Journal of Science Education \& Technology, 20(3), 215-232. https://doi.org/10.1007/s10956-010-9247-2.

Kukharenko V. (2013) Zmishane navchannia. Teoriia ta praktyka zmishanoho navchannia: monohrafiia [Blended Learning. Theory and Practice of blended learning: monograph]. Kharkiv, Ukraine: Miskdruk.

Liashchenko O., Babiy S. (2017) Designing virtual learning environment for teaching English for Special Purposes. Intellectual Archive, 6 (3), 92-101.

O'Byrne, W. I., \& Pytash, K. E. (2015). Hybrid and blended learning. Journal of Adolescent \& Adult Literacy, 59(2), 137-140.

Peterson, L. A. \& McGuire, D. M. (2014). Gearing up for hybrid teaching and learning : Ch-Ch-Ch-Ch-Changes! Higher Learning Commission Annual Conference 2014, Collection of Papers.

Pombo, L., \& Moreira, A. (2010). Evaluation practices of teaching and learning in Portuguese Higher Education blended learning modules. In M. B. Nunes, \& M. McPherson (Eds.). Proceedings of International Conference e-Learning (pp. 267-274) (Vol 1). Freiburg, Germany.

Torrisi-Steele, G., \& Drew, S. (2013). The literature landscape of blended learning in higher education: The need for better understanding of academic blended practice. International Journal for Academic Development, 18(4), 371-383.

Usova, T. (2011). Optimizing our teaching: Hybrid mode of instruction. Partnership: The Canadian Journal of Library and Information Practice and Research, 6(2), 1-12. 